\title{
Influence of thermomechanical aging on fatigue behaviour of 2014 Al-alloy
}

\author{
S SINGH and D B GOEL* \\ Department of Metallurgical and Materials Engineering, Indian Institute of Technology, Roorkee 247 667, India
}

MS received 17 January 2005

\begin{abstract}
The fatigue behaviour of 2014 Al-alloy has been studied in various thermomechanically aged conditions. It is observed that fatigue properties can be improved by a thermomechanical treatment, which would reduce the concentrations of dispersoids, provide a relatively uniform deformation structure and produce fine distribution of $\theta^{\prime}$ precipitates. Fine $\theta^{\prime}$ particles inhibit dynamic recovery and produce uniform deformation structure, which improves fatigue behaviour. Presence of dispersoids and coarse precipitate particles leads to the formation of persistent slip bands (PSBs) and a highly heterogeneous deformation structure, which cause damage to fatigue properties.
\end{abstract}

Keywords. Dispersoids; thermomechanical aging (TMA); striations; precipitate-dislocation tangles.

\section{Introduction}

Aluminium alloys find wide application in a variety of uses because of various characteristics, such as high corrosion resistance, good workability and excellent mechanical and tribological properties. These alloys are extensively used in automobile and aircraft industries. Fatigue is an important parameter in various applications involving constant and variable amplitude of loading. Various metallurgical and environmental factors influence the fatigue resistance of engineering components. The results reported in the literature on the influence of thermomechanical aging (TMA) on the fatigue properties of Alalloys are not consistent. Some workers (Broek and Bowles 1971; Ostermann 1971; Malakondaiah and Rama Rao 1977; Harendranath and Mallik 1982; Sadeler et al 2004; Ali 2005) reported an appreciable improvement in fatigue properties after TMA treatment, whereas some others (Lyst 1968; Di Russo et al 1973; Reimann and Brisbane 1973) reported either no effect or detrimental effect on fatigue properties. Malakondaiah and Rama Rao (1977) and Broek and Bowles (1971) successfully stabilized the precipitate structure in 2000 series Al-alloys by suitable TMA treatments and claimed a $25 \%$ improvement in the fatigue values. Ostermann (1971) and Harendranath and Mallik (1982) claimed almost the same amount of improvement in fatigue properties of 7000 series Alalloys through TMA treatment. Reimann and Brisbane (1973) using the same materials as Ostermann (1971), found no effect of TMA on fatigue properties. Di Russo et al (1973) showed that TMA produced lower fatigue strength than that obtained by conventional aging treat-

*Author for correspondence ment. Uygur et al (2004), Uygur and Kulekei (2002) and Chawla et al (1998) studied the effect of particulates on fatigue properties of 2000 series Al-alloys and observed that large particulates or intermetallic particles (dispersoids) are potential nucleation sites for fatigue cracks. Combined influence of dispersoids and the microstructure developed as a result of TMA, however, have not been studied systematically to date. The present investigation has been undertaken to explore the best combination of thermal and mechanical treatments, which may modify suitably the microstructure so as to cause an overall improvement of fatigue properties of 2014 Al-alloy.

\section{Experimental}

The alloy used in this investigation was prepared from $\mathrm{Al}$ of $99.70 \%$ purity and $\mathrm{Cu}, \mathrm{Si}, \mathrm{Mn}$ and $\mathrm{Mg}$ of $99.9 \%$ purity. The cast alloy was homogenized at $500^{\circ} \mathrm{C}$ and hot rolled at $425^{\circ} \mathrm{C}$. The $2014 \mathrm{Al}$-alloy had the composition (wt.\%): $4.44 \mathrm{Cu}, 0.85 \mathrm{Si}, 0.77 \mathrm{Mn}, 0.45 \mathrm{Mg}$ and balance Al.

The normal aging behaviour of the $2014 \mathrm{Al}$ alloy without any thermomechanical treatment has been described in an earlier paper (Singh and Goel 1991). In the solution treated condition an hardness of $59 \mathrm{VHN}$ is obtained. On aging at $160^{\circ} \mathrm{C}$ the alloy attains a peak hardness of $114 \mathrm{VHN}$. In this study, various TMA treatments involved pre aging to 25 and $50 \%$ of the peak aged hardness value and warm rolling at $160^{\circ} \mathrm{C}$ to 10 and $20 \%$ after the pre aging treatments. The various TMA treatments given to the alloy under investigation are designated and described as under:

AQ: Solution treatment at $500^{\circ} \mathrm{C}$ for $1.5 \mathrm{~h}$, followed by quenching in water. 
PA: AQ treatment, followed by peak aging at $160^{\circ} \mathrm{C}$, followed by quenching in water.

TMA Ia: AQ treatment, followed by $25 \%$ pre aging at $160^{\circ} \mathrm{C}$ (up to $73 \mathrm{VHN}$ ), followed by $10 \%$ warm rolling at $160^{\circ} \mathrm{C}$, followed by final aging at $160^{\circ} \mathrm{C}$ to peak value, followed by quenching in water.

TMA Ib: AQ treatment, followed by $25 \%$ pre aging at $160^{\circ} \mathrm{C}$, followed by $20 \%$ warm rolling at $160^{\circ} \mathrm{C}$, followed by final aging at $160^{\circ} \mathrm{C}$ to peak value, followed by quenching in water.

TMA IIa: AQ treatment, followed by $50 \%$ pre aging at $160^{\circ} \mathrm{C}$ (up to $87 \mathrm{VHN}$ ), followed by $10 \%$ warm rolling at $160^{\circ} \mathrm{C}$, followed by final aging at $160^{\circ} \mathrm{C}$ to peak value, followed by quenching in water.

TMA IIb: AQ treatment, followed by $50 \%$ pre aging at $160^{\circ} \mathrm{C}$, followed by $20 \%$ warm rolling at $160^{\circ} \mathrm{C}$, followed by final aging at $160^{\circ} \mathrm{C}$ to peak value, followed by quenching in water.

Fatigue studies on samples after various treatments were made on Whoeler type fatigue testing machine. $S-N$ curves were obtained using round bar shaped specimens of $8 \mathrm{~mm}$ diameter and $85 \mathrm{~mm}$ gauge length. Stress levels selected for fatigue tests were 177, 157, 137, 118 and $98 \mathrm{~N} \cdot \mathrm{mm}^{-2}$. The tests were first conducted at the highest level of stress $\left(S=177 \mathrm{~N} \cdot \mathrm{mm}^{-2}\right)$ and then in descending order of stress magnitude. The maximum number of cycles $(N)$ up to which the fatigue tests were conducted was kept at $10^{7}$. Tests were conducted on three specimens for every point of $S-N$ curve.

Extensive metallographic studies were carried out to study the effect of various TMA treatments on structural parameters which influence the fatigue properties. Structural changes during TMA treatments were studied with the help of Metavert optical microscope and Philips EM400 transmission electron microscope (TEM). For TEM studies thin foil samples were prepared by window technique at $12 \mathrm{~V}$ and $70^{\circ} \mathrm{C}$ using an electrolyte of volumetric composition: $\mathrm{H}_{3} \mathrm{PO}_{4} \quad 62 \%+\mathrm{H}_{2} \mathrm{O} \quad 24 \%+\mathrm{H}_{2} \mathrm{SO}_{4}$ $14 \%$ and $\mathrm{CrO}_{3} 160 \mathrm{~g} / \mathrm{l}$. The mode of fracture during fatigue failure was examined on Philips SEM501 scanning electron microscope (SEM).

\section{Results}

\section{$3.1 S-N$ curves}

The $S-N$ curves at various stress levels for various treatments are given in figure 1 . It is seen from the curves that at any stress level the alloy in the PA condition has the lowest fatigue life. All TMA treatments, except TMA IIa, provide improvement in fatigue properties with respect to AQ and PA conditions. The stress level in AQ specimens is only slightly higher than that in TMA IIa. The best fatigue properties are observed in the alloy after TMA Ib treatment. In both 25 and $50 \%$ pre aged conditions it is seen that $20 \%$ deformation is more effective in improving the fatigue properties than $10 \%$ deformation. The alloy in $25 \%$ pre aged condition possesses better fatigue properties than in the $50 \%$ pre aged condition. The dotted lines in the $S-N$ curves indicate that the specimens given TMA Ia and TMA Ib treatments did not fail even after $10^{7} \mathrm{cy}-$ cles at 118 and $98 \mathrm{~N} \cdot \mathrm{mm}^{-2}$ stress levels.

The $S-N$ curves have a tendency to converge at high stress levels and tend to diverge as the stress level is decreased, indicating that the relative effect of TMA treatment increases as the stress level during fatigue test is lowered, i.e. in the high cycle range the TMA treatments are most effective in improving fatigue properties. From figure 1 it is also seen that for any value of fatigue life the corresponding fatigue stress (endurance limit) of the alloy after TMA Ib treatment (which gives best fatigue properties) is constantly higher by a margin of $\sim 25-35$ $\mathrm{N} \cdot \mathrm{mm}^{-2}$ from the value obtained in the PA condition throughout the range of investigation.

\subsection{TEM study}

The TMA treatments have been observed to affect substantially the aging characteristics and the resultant microscopic structure of the alloy. The TEM study shows that the TMA Ib treatment yields finest $\theta^{\prime}$ needles having longitudinal dimension of $\sim 400 \AA$. Coarsest size $\theta^{\prime}$ needles $(850 \AA)$ are observed in PA treatment. The TMA treatments, besides affecting the aging kinetics, also lead to dislocation-precipitate networks of different magnitudes. In the present study it is observed that treatments involving 20\% warm rolling (TMA Ib and TMA $1 \mathrm{Ib}$ ) result in development of thick dislocation-precipitate tangles. Figure 2 shows dislocation-precipitate tangles for TMA $\mathrm{Ib}$ and TMA IIb treatments. It is seen that TMA Ib results in a fine and uniform network of such tangles, whereas in

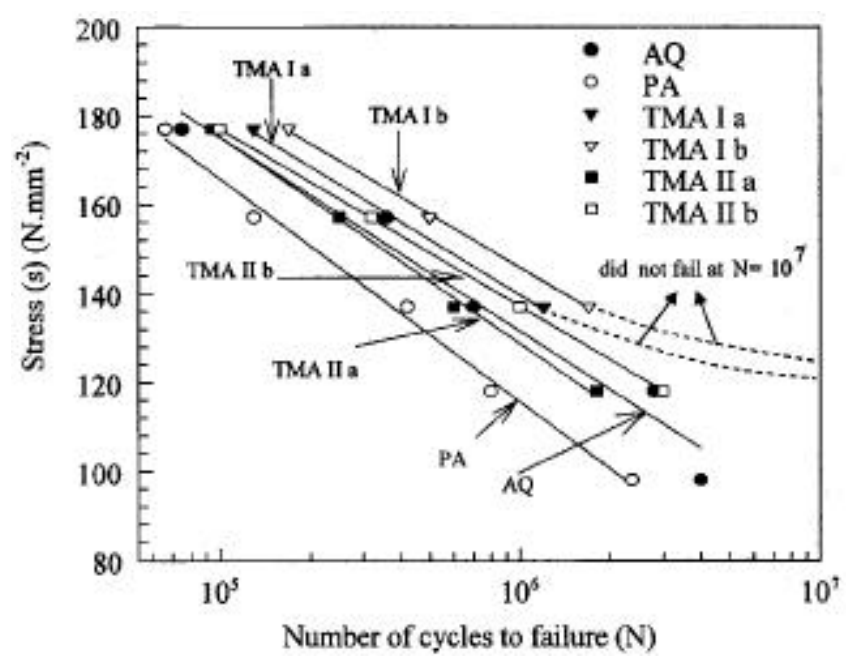

Figure 1. $S-N$ curves of $2014 \mathrm{Al}$-alloy after various treatments. 
TMA IIb the dislocation-precipitate networks are coarse and nonuniformly distributed. It is observed that the nature of these networks is an important parameter affecting the fatigue properties.

\subsection{Optical microscopy}

In optical microscopic study two types of (intermetallic particles) dispersoids (Singh 1985) have been observed, which have been identified as $\mathrm{Al}_{4} \mathrm{CuMg}_{5} \mathrm{Si}_{4}$ and $\mathrm{Al}_{12}(\mathrm{Fe}$, $\mathrm{Mn})_{3} \mathrm{Si}$ (figure 3). Maximum concentration of dispersoids is observed in PA specimens. It has been observed that there is a drastic reduction in the concentration of these dispersoids due to various TMA treatments. The TMA Ib treatment causes maximum reduction in the concentration and size of dispersoids. After the TMA IIb treatment the dispersoids are in small number, but of larger size as compared to AQ and TMA Ib treatments. The presence of dispersoids has been observed to play a vital role in the fatigue properties. In addition to their effect on nucleation, dispersoids can also increase the rate of crack propagation.

\subsection{SEM study}

The SEM study reveals that in high cycle fatigue the failure may be basically by (i) dispersoids and (ii) formation of dense striation networks. Figure 4 gives SEM micrographs of fatigue fracture surfaces. In figure 4(a) it is seen that intermetallic particles (dispersoids) play a vital role in the nucleation of fatigue cracks. During fatigue cracks are formed either by cracking and fragmentation of the dispersoids themselves, or at the interface of the dispersoids with the matrix. The crack fronts advance into the matrix leading to final fracture. The striations formed at various stages of crack advancement are seen in the SEM micrographs. Whenever an advancing crack front meets other dispersoids, further nucleation of fatigue cracks takes place. Localization of high density fatigue striations also lead to crack nucleation, as seen in figure 4(b). The characteristic appearance of striations is observed to vary widely from treatment to treatment. In the AQ samples the striations are observed to be more or less straight and parallel, whereas in the PA samples the striations are in general irregular, ill defined and broken, but in some regions the fracture surface also shows the formation of nearly straight striations. The mechanism of crack formation in the TMA specimens appears to be the same as in the AQ and PA ones. The fatigue behaviour as noted from the $S-N$ curves in figure 1 is supported by SEM study.

Treatments, which cause improvement in fatigue life, exhibit formation of a large number of fine ductile dimples. In figure 4(c) unequiaxed ductile dimples are shown in the TMA Ib specimen. Low fatigue life is indicated by existence of fast fracture features as seen in figure 4(d), which represents a SEM fractograph from a TMA IIb specimen.

\section{Discussion}

Important microstructural features, which significantly affect the fatigue properties of $2014 \mathrm{Al}$ alloy after various TMA treatments, are mainly (i) dispersoids, (ii) strengthening precipitates $\left(\theta^{\prime}\right)$ and (iii) dislocation networks. Of all the factors, the presence of dispersoids is known to play a dominant role in fatigue crack nucleation in $\mathrm{Al}$ alloys (Ruch and Gerold 1982; Tanaka and Mura 1982; Siglu et al 1983; Singh 1985; Chawla et al 1998; Uygur and Kulekei 2002; Uygur et al 2004). Their importance in nucleating fatigue cracks relates to three factors: (i) a hard dispersoid can act as a stress concentrator, thereby localizing deformation in much the same way as a notch, (ii) debonding may occur along the dispersoid/matrix interface and (iii) the relative brittleness of intermetallic
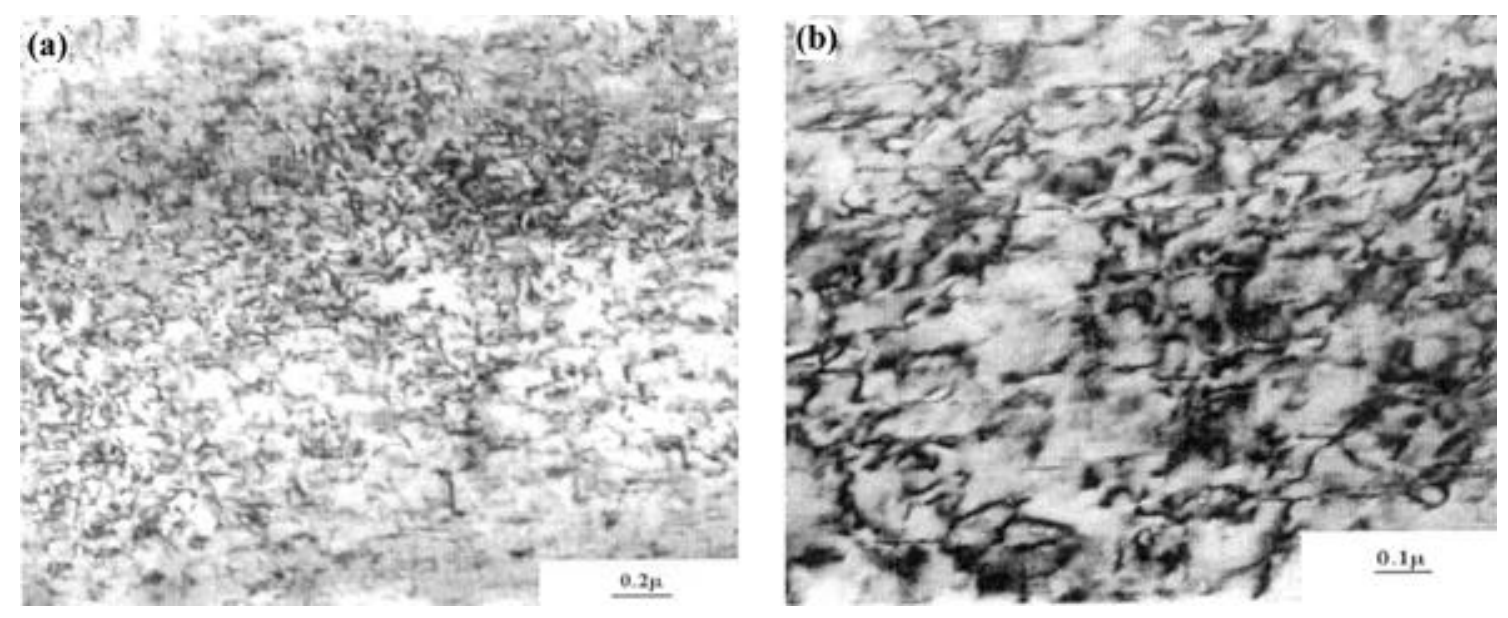

Figure 2. Transmission electron micrographs of TMA treated specimens showing dislocation-precipitate tangles: (a) TMA Ib and (b) TMA IIb. 
compounds allows the possibility of precracking during forming operation as seen in figure 4(a). In addition to their effect on nucleation, dispersoids can also increase the rate of stage II crack propagation by nucleating cracks ahead of the main advancing crack. The present study confirms the vital role played by dispersoid particles in affecting the fatigue properties. The optical microscopic examination (figure 3 ) reveals the existence of large concentration of dispersoids in PA specimen, which, as shown in figure 1 , also depicts poorest fatigue properties. The improvement in fatigue properties after various TMA treatments can be attributed mainly to the drastic reduction in the concentration of these dispersoids as is revealed by optical metallographic observation. TMA Ib results in maximum elimination of dispersoids, and accordingly exhibits the best fatigue properties.

Structural heterogeneities developed due to cyclic deformation also play considerably vital role in the fatigue mechanism. For example, the PSBs contribute significantly to fatigue crack nucleation, which is promoted by bandmatrix decohesion (Ruch and Gerold 1982; Vogel et al 1982). A highly heterogeneous deformation structure con-
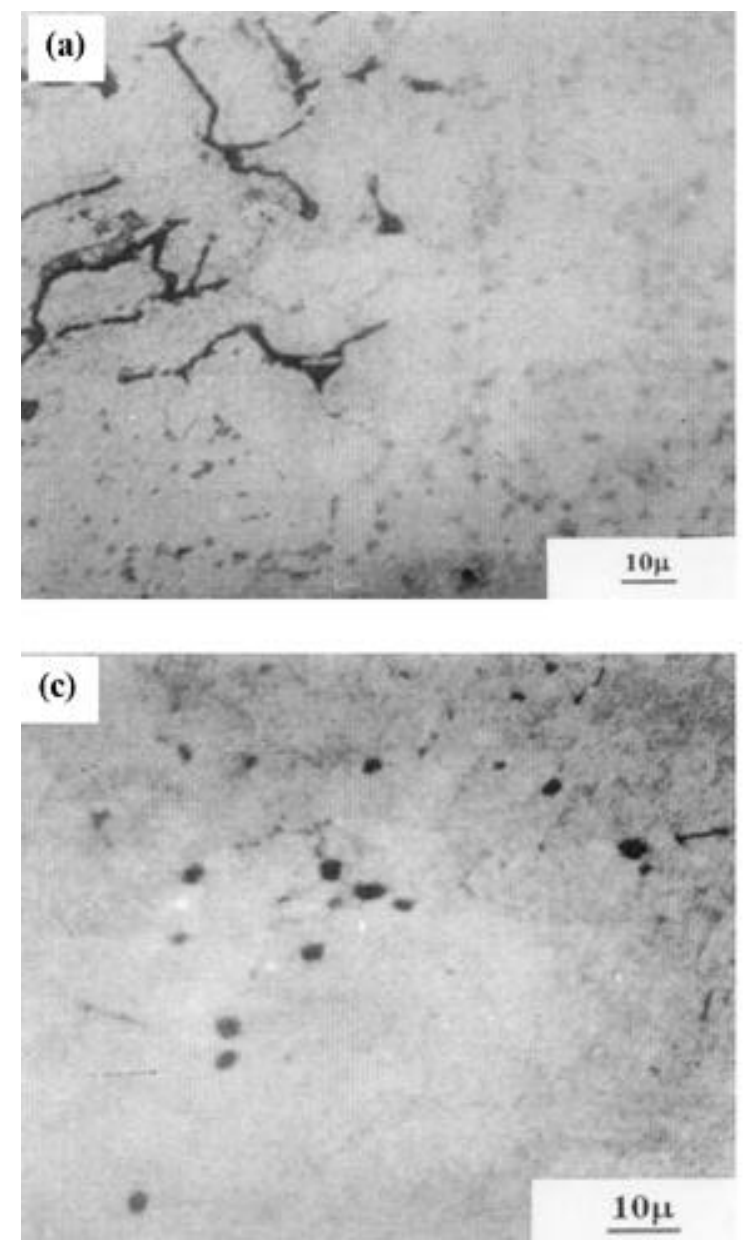

sisting of PSBs and cell walls provides paths along which crack growth is facilitated. In view of this, a material capable of a high degree of dynamic recovery would be expected to behave poorly in fatigue, since the recovery accelerates the formation of intense cell walls and slip bands. Since the $\theta^{\prime}$ precipitates nucleate preferentially at dislocations and significantly control the deformation structure in the $2014 \mathrm{Al}$ alloys, they also play an important role in influencing the fatigue properties of this alloy. Fine $\theta^{\prime}$ precipitates lead to better fatigue properties, because fine size precipitates inhibit dynamic recovery, thereby hindering the formation of PSBs and intense cell walls. The remarkable improvement in fatigue properties in TMA Ib treated specimens is also due to fine and uniform networks of $\theta^{\prime}$ precipitate-dislocation tangles as seen in figure 2(a).

Another factor affecting fatigue is impact of cyclic loading on the precipitation structure of age hardenable Al alloys as put forward by several investigators (Papazian et al 1980; Pahl Jr and Cohen 1984). Generally the fatigue stresses applied are much lower than the yield stress of the material. Thus a single application of fatigue
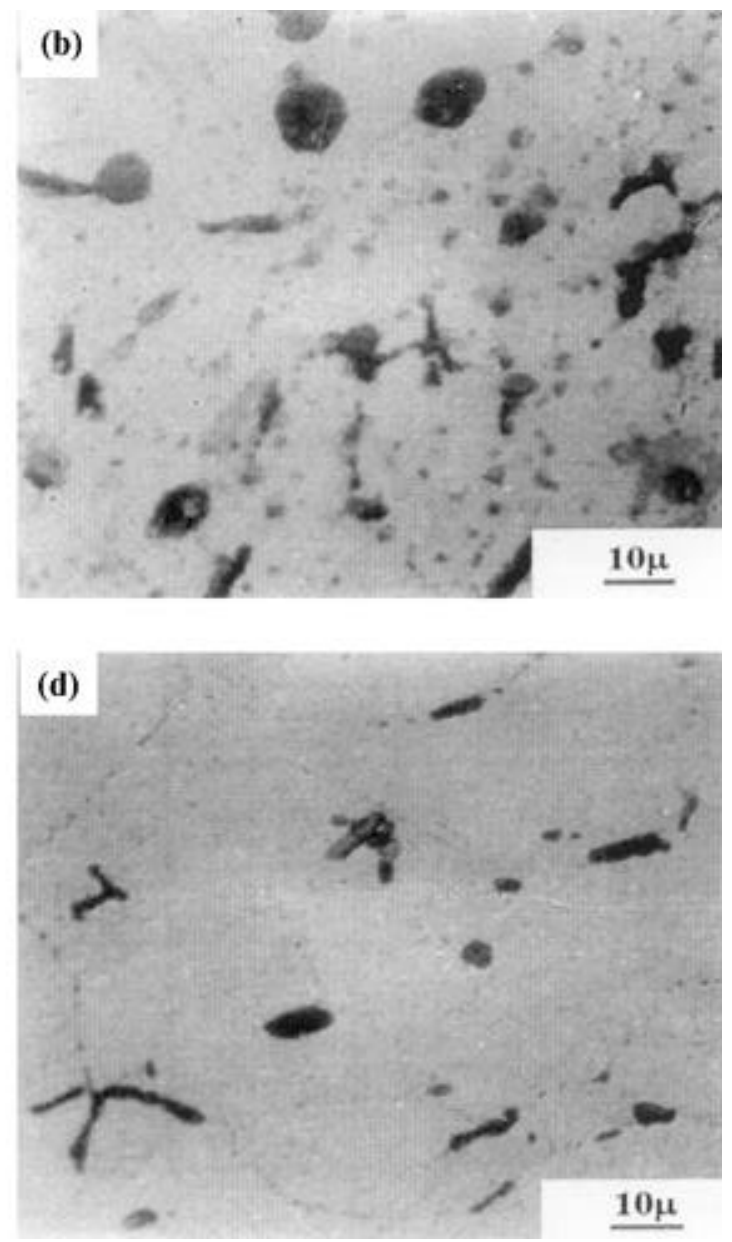

Figure 3. Optical micrographs showing (i) light etching $\mathrm{Al}_{4} \mathrm{CuMg}_{5} \mathrm{Si}_{4}$ and (ii) dark etching $\mathrm{Al}_{12}(\mathrm{Fe}, \mathrm{Mn})_{3} \mathrm{Si}$ dispersoids: (a) AQ, (b) PA, (c) TMA Ib and (d) TMA IIb. 
stress has very little probability of causing any significant dislocation movement; but if the stress is applied many times, there is a chance that eventually some local slip will occur. Local dislocation movements generate vacant lattice sites, thus increasing the local diffusion rates. This increased local diffusion causes localized effects similar to high temperature aging. This phenomenon results in localized coherent precipitation in solution treated specimens and further aging in partially aged alloy. This will also cause overaging in fully hardened specimens. In this view, the maximum overaging effects are expected in the PA specimens, since the $\theta^{\prime}$ precipitates are coarsest in PA condition. This overaging effect causes $\theta^{\prime}$ precipitates to behave in the same way as the dispersoids in nucleating and propagating the fatigue cracks. Thus the fatigue properties of PA samples, which are already very poor due to the presence of dispersoids, are further deteriorated due to coarsening of $\theta^{\prime}$ precipitates caused by cyclic stresses.

The SEM studies in the present investigation show striations on the fracture surface, which are indicative of positions during motions of the crack front. These striations are related to the formation of PSBs which are continually formed ahead of the crack tip. Earlier TEM studies of the deformation structure adjacent to the fracture surfaces have established that striations are related to the nonuniform dislocation substructure (Wanhill 1975; Nix and Flower 1982). Nix and Flower (1982) using combined SEM/TEM observations have shown that the dislocation band spacing corresponds to that of the surface striations and that the dislocation bands also correspond to the position of the fatigue crack front at some stage during the fatigue cycle. Thus existence of striations on the SEM fractographs can be correlated with that of high density dislocation bands produced during fatigue. Since such bands lead to band-matrix decohesion due to high stress concentration, cracks would also be detected at dense striation walls in the SEM fractographs as shown in figure 4(b). The occurrence of well defined regular striations observed in the AQ condition as seen in figure 4(a) is attributed to a large number of available slip systems and the ease of cross slip allowing the material to
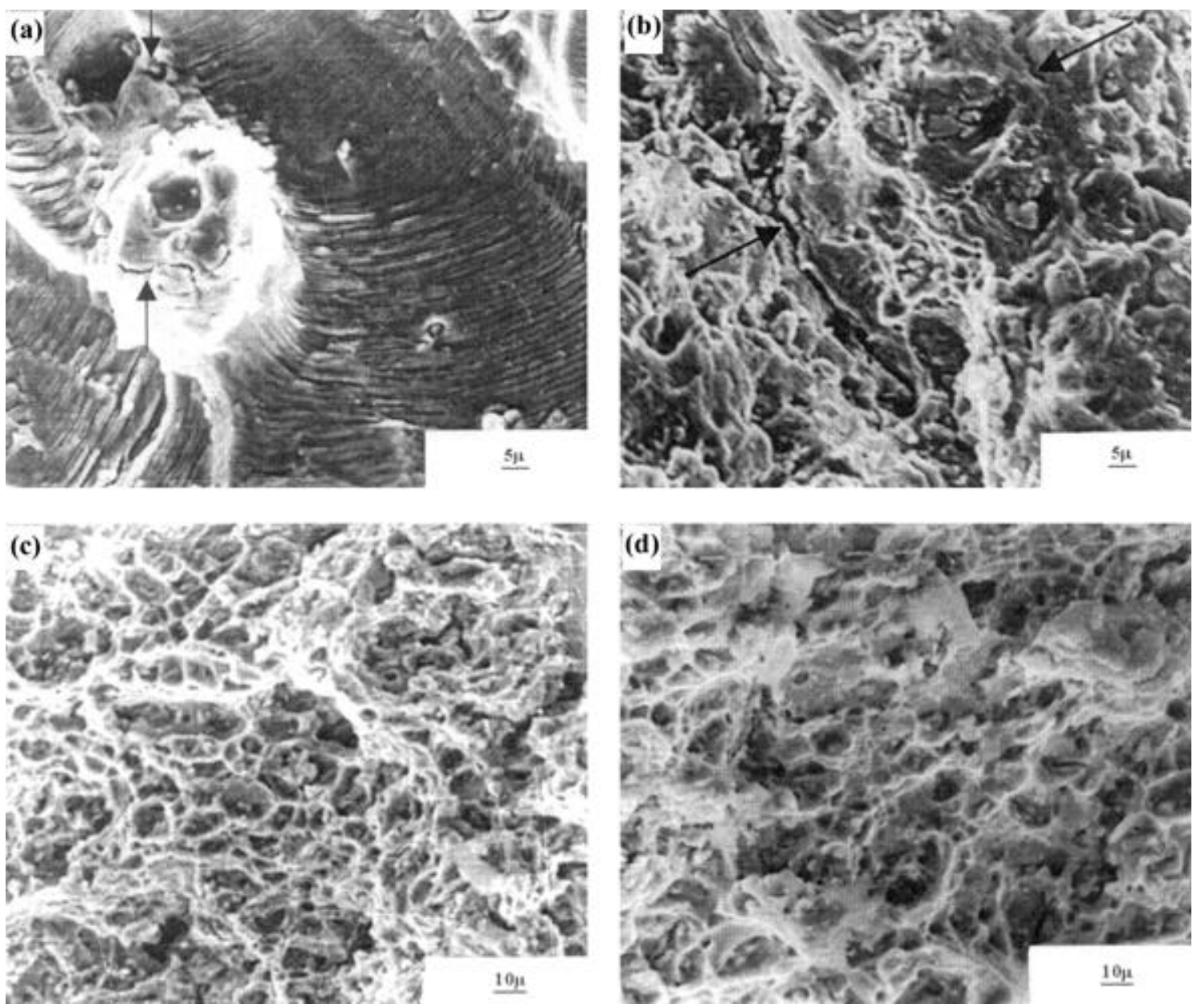

Figure 4. SEM fractographs of fatigue tested specimens: (a) crack nucleation at dispersoids in AQ specimens, (b) crack nucleation at tangles of striations in PA specimens, (c) unequiaxed ductile dimples in TMA Ib specimens and (d) fast fracture features in TMA IIb specimens. 
perfectly accommodate the deformation required by an irregular crack front. The striations in the PA sample, however, are wavy and ill defined due to the presence of large dispersoids and overaging of $\theta^{\prime}$ particles as seen from figure 4(b). The fractographs of samples after various TMA treatments show fine networks of close loop striations (figures 4(c) and (d)), because the plastic deformation is localized due to the presence of fine sized $\theta^{\prime}$ precipitates, which is indicative of high fatigue strength. Fine $\theta^{\prime}$ particles inhibit cross slip and thus localize the plastic deformation occurring at the crack tip of the advancing front. Fine $\theta^{\prime}$ particle-dislocation networks also inhibit fatigue crack propagation, thereby causing improvement in fatigue properties. The alloy after TMA Ib treatment yields uniform and finest distribution of $\theta^{\prime}$ dislocation tangles, and accordingly the striation loops formed in the sample after this treatment are also finest as seen in figure 4(c). Fine distribution of unequiaxed ductile dimples in the fractograph is in agreement with remarkable improvement in fatigue properties by TMA Ib treatment.

\section{Conclusions}

On the basis of the above discussion it is found that in the 2014 Al-alloy fatigue properties can be improved by a thermomechanical treatment, which would (i) reduce the concentration of dispersoids, (ii) provide a relatively uniform deformation structure and (iii) produce a fine distribution of $\theta^{\prime}$ precipitates. From these considerations, the maximum improvement in fatigue properties is caused by TMA Ib treatment, whereas, TMA IIa results in poor fatigue behaviour. It is also observed that all TMA treatments cause improvement in the fatigue properties with respect to the PA condition, which corresponds to poorest fatigue properties. The relative difference in fatigue life after various treatments is due to the combined effect of various controlling parameters.

\section{References}

Ali M 2005 Int. J. Fatigue 2733

Broek D and Bowles C O 1971 J. Inst. Metals 99255

Chawla N, Andres C, Jones J W and Allison J E 1998 Met. Trans. A29 2843

Di Russo E, Conserva M, Gatto F and Maricus F 1973 Met. Trans. A4 1133

Harendranath C S and Mallik A K 1982 Trans. IIM 35415

Lyst J O 1968 J. Mater. 3996

Malakondaiah G and Rama Rao P 1977 Proc. 4th Int. conf on fracture, Waterloo (Canada) (New York: Pergamon) 2B p. 741

Nix K J and Flower H M 1982 Acta Met. 301549

Ostermann P 1971 Met. Trans. 22897

Pahl Jr R G and Cohen J B 1984 Met. Trans. A15 1519

Papazian J M, Deiasi R J and Adier P N 1980 Met. Trans. A11 135

Reimann W H and Brisbane A W 1973 Eng. Fracture Mechanics $\mathbf{5} 67$

Ruch W and Gerold V 1982 Proc. 4th ECF Conf. Leoben (Austria) p. 383

Sadeler R, Totik Y, Govgali M and Kaymaz I 2004 Materials and Design 25439

Siglu D, Mortpetit M C and Haworth W L 1983 Met. Trans. A14 931

Singh S 1985 Thermomechanical ageing of 2014 aluminium alloy, $\mathrm{PhD}$ Thesis, University of Roorkee, Roorkee

Singh S and Goel D B 1991 Bull. Mater. Sci. 1435

Tanaka K and Mura T 1982 Met. Trans. A13 117

Uygur I and Kulekei M K 2002 Turk. J. Eng. Environ. Sci. 44265

Uygur I, Evans W J, Bache M and Gulen B 2004 Materials and Design (in press, available at www.sciencedirect.com)

Vogel W, Wilhelm M and Gerold V 1982 Acta Met. 3921

Wanhill R J H 1975 Met. Trans. A6 1587 